\title{
Dynamic analysis of a multi-span simply supported prestressed concrete bridge with restrainers and seismic isolation devices
}

\author{
Ouanani M 1,3*, Sandjak K ${ }^{2,3}$, Tiliouine $\mathrm{B}^{3}$
}

1 Université de Djelfa, Faculté des Sciences et de la Technologie, Djelfa, ALGERIA.

2 Département de Génie Civil, Faculté des Sciences de l'Ingénieur, Université M'Hamed Bougara, 35000, Boumerdes, ALGERIA.

3 Ecole Nationale Polytechnique, Département de Génie Civil, Laboratoire de Génie Sismique et de Dynamique des Structures, 10 Avenue des Frères Oudek, Hassen Badi, BP. 182, 16200, El Harrach, Alger, Algérie Dynamics, Alger, ALGERIA

* CorrespondingAuthor:mouloud.ouanani@g.enp.edu.dz, m.ouanani@univ-djelfa.dz

Received: 16-06-2020

Accepted: 24-08-2020

\begin{abstract}
The Nonlinear F.E. code Structural Analysis Program (SAP) in which the primary nonlinear characteristics of bearings, impact elements and steel restrainer cables considered herein in order to investigate the dynamic analysis of a multi-span simply supported MSSS prestressed concrete bridge, equipped with steel restrainer cables and Lead Rubber Bearings LRB devices includingSoil Structure Interaction (SSI) effects. A MSSS bridge with restrainer cables and lead rubber bearings at the two abutments and intermediate bents located in North Algeria is selectedaccording to RPOA for seismic design category 1 is considered in this study.A detailed 3D nonlinear analytical model of study bridge subjected to three components identical seismic excitation includingpounding elements, restrainer cables and bearing devices at expansion jointsis developed. The nonlinear characteristics of theses boundary elements are represented by bilinear hysteretic models. Under strong seismic excitations, the large longitudinal displacementsresult the collision between bridge decks or even unseating of these decks at expansion joints of MSSS bridge. Finally,the study reveals among others that in order to prevent deck unseating resulting from restrainer failures and subsequent bridge collapse, particular attention should also be given to proper design of nonlinear characteristics of restrainers and bearing devices.
\end{abstract}

Key words: Nonlinear F.E., Soil structure interaction, pounding elements, restrainer cables, lead rubber bearings

\section{Introduction}

The multi-span simply supported MSSS prestressed concrete bridgesare frequently used in highway bridgesrepresenting an essential component of transportation networks. This categorie of bridges presentsvarious advantages such as, fast construction, convenient manufacture and installation and their adjacent bridge decks are connected at expansion joints in order to accommodate temperature and deformations induced by shrinking and creep of prestressed concrete. Unfortunately, the expansion joints between adjacent decks or between deck and abutment become vulnerable components under severe ground motions, because of the superstructure pounding which may induce the local failure of the deck itself and unseating damage.

However, the MSSS highway bridge damages due to pounding impact at the expansion joints of girders and abutments and unseating have been particularlyobserved in several seismic events, (e.g. Wenchuan earthquake (Hung et al., 2008), Boumerdes earthquake (AFPS, 2003), Chi-Chi earthquake (Uzarski and Arnold, 1999), Kobe earthquake (Chouw,1995) and Northridge earthquake (Todd et al., 1994)). In particular, the Chi-Chi earthquake (1999) in Taiwan revealed hammering at the expansion joints in some bridges which resulted in damage to shear keys, bearings and anchor bolts (Uzarski and Arnold, 2001). Based on these observations, pounding 
can cause crashing and spalling of concrete at the impact locations, result in damage to column bents, abutments, shear keys, bearing pads and restrainers, and possibly contribute to the collapse of deck spans.

Many previous works have been conducted to investigatethe fragility of highway bridges under uniform ground motions (Shinozuka et al., 2003; Desroche and Muthamar, 2004; Hong et al., 2019) and non uniform ground motions (Yang et al., 2018), they corroborated that the multispan simply supported MSSS prestressed concrete bridges are most vulnerable to pounding damage due to the discontinuity in the superstructure at multi-column bents. In particular, Hong et al. (2019) investigated the effect of the nonlinear impact on the longitudinal response of multi-span simply supported bridges under strong earthquakes and they concluded that the collision parameters affect the responses of the multi-span simply supported beam bridge subjected to ground motions. Further researches by Bi et al. (2013) and Yang et al. (2018) have also studied extensively the impact of spatially varying ground motions on the seismic response of bridges when pounding was either considered or not considered.

In addition to above pratical justifications, the damage data of bridges have also illustrated thatthe bridge components structural performance may be very sensitive to 3D components of ground motions (Tiliouine and Ouanani, 2012) and foundation soil flexibility including abutment-backfill soil (Ouanani and Tiliouine, 2017).

This paper presents some results from an exhaustive investigation carried out on the dynamic analysis of amulti-span simply supported MSSS prestressed concrete bridge equipped with retrainers and seismic isolation devices at expansion joints and abutments including Soil Structure Interaction (SSI) effects. In this context, The nonlinear time history analyses using detailed 3D Finite Element Model FEM of a MSSS bridge located in North Algeria are performed to assess the performance of the steel restrainer cables and Lead Rubber Bearing devices LRB under the 3D components of severe seismic excitation. Nonlinear characteristics of the impact and restrainer elements at expansion joints and bearing devices at the seat-abutments and intermediate bents of study bridge are represented by nonlinear hysteretic models. These nonlinear properties are considered in the dynamic analysis of amulti-span simply supported concrete bridge. These considered nonlinearities include the width of expansion joint, the impact stiffness of colliding spansand the longitudinal stiffness of the bearing device in the seismic analysis in order to predict or to avoid the collision damages in bridge structures. In order to include the SSI effects, the effective stiffness, foundation soil damping at the base of the spread footings have been evaluated using procedure guidelines (FEMA, 2000).

\section{Description and 3-D nonlinear analytical modelind of MSSS prestressed concrete bridge}

\subsection{Description of MSSS prestressed concrete bridge}

Fig. 1 shows details of typical MSSSpre-stressed concrete girder bridge located on the East-West highwayjoining the BouiraCity in Eastern Algeria. The bridge consideredin this study isstraight with slope of $4.60 \%$ and consists of a three discontinued decksreinforced concrete of $13.1 \mathrm{~m}$ wide and equal length of $35.85 \mathrm{~m}$ (Figures. 1(a), 1(b))and supported by seven prestressed concrete T girders (Figure 1(c)).

The bridge with an overall length of $107.77 \mathrm{~m}$ is supported on multi-column bents of equal height of $19.3 \mathrm{~m}$ and two seat-type abutments.Each column has a circular cross-section with $1.8 \mathrm{~m}$ diameter (Figure $1(\mathrm{~d})$ ).

The bridge consists of four expansion joints in steel of type Wd110, located on the two Multicolumn bentsand the two abutments. Each pre-stressed concrete T-shaped girder is supported at abutments and bents by the Lead Rubber Bering device LRB. 

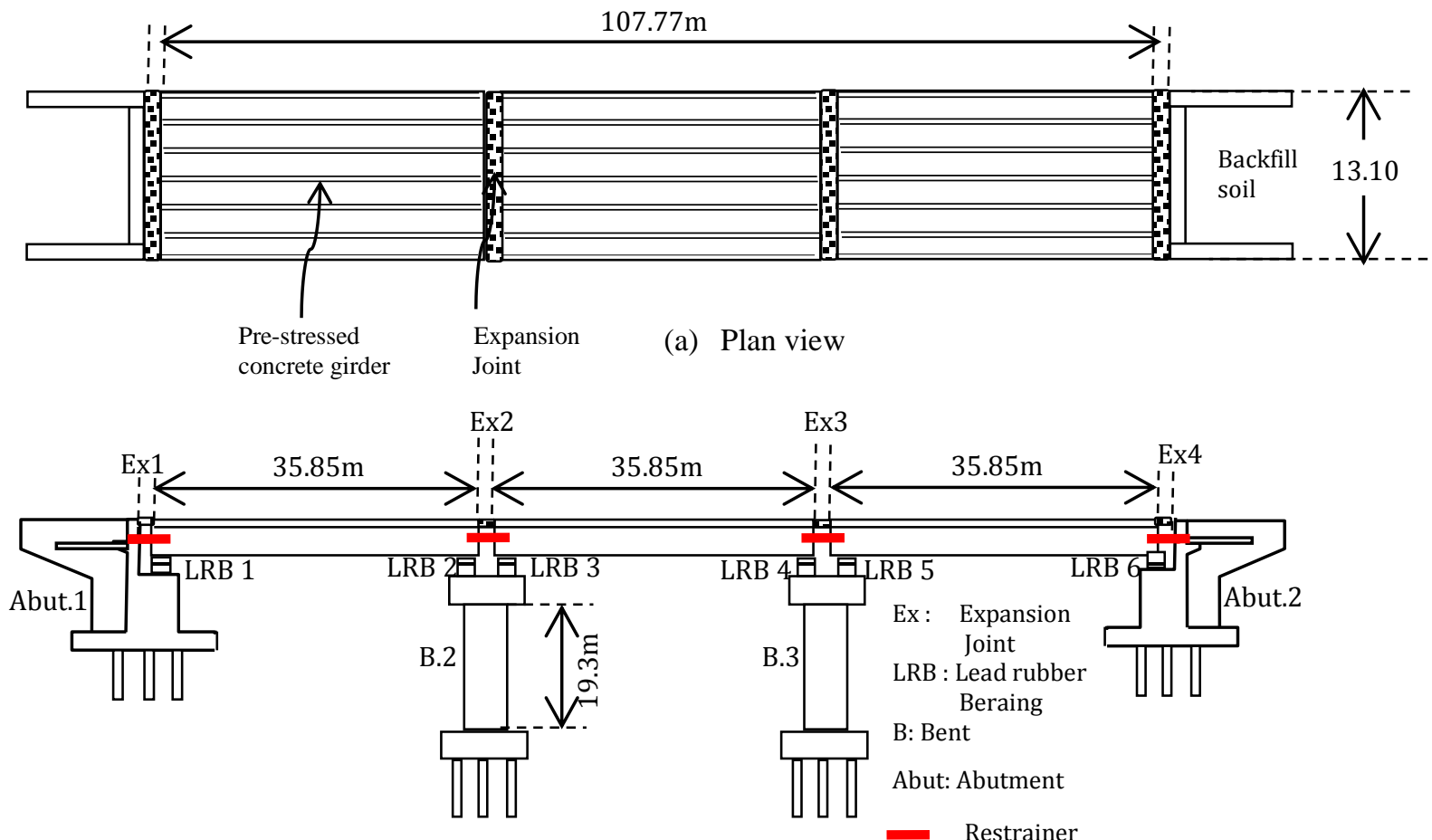

(b) Elevation view: Longitudinal direction

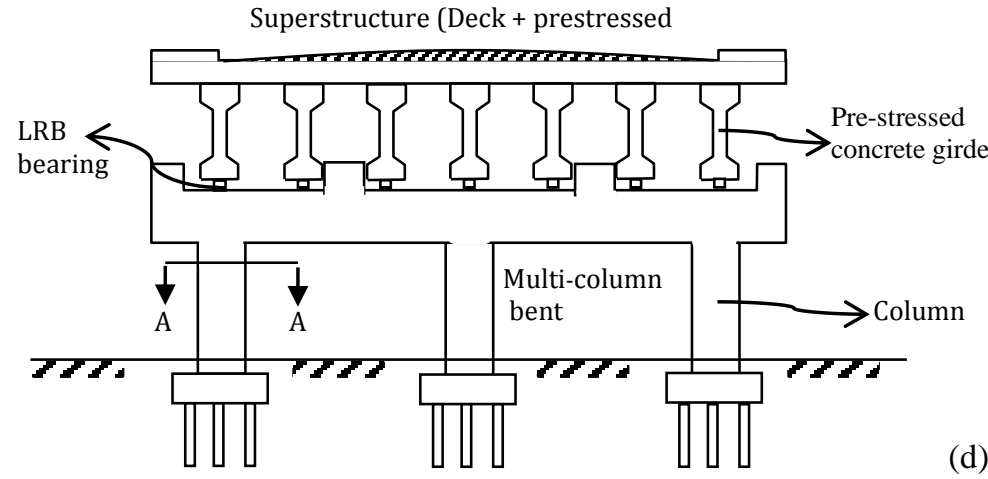

(d) Column section

(c) Bent elevation: Transverse direction

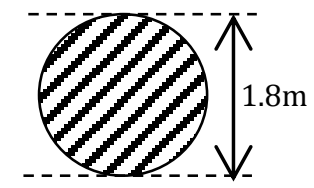

A-A

Fig 1. General description of MSSS prestressed concrete bridge.

\subsection{D nonlinear analytical modeling of MSSS prestressed concrete bridge}

The MSSS bridge with steel restrainer cables and lead rubber bearings at two abutments and intermediate bents considered in this study is analytically modeled as a lumped mass system. Thus, a 3D nonlinear analytical model of a bridge is developed using the Nonlinear F.E. code (CSI Bridge, 2015). The superstructure and multi-columns bents of bridge are modelled as elasticbeam elements, while bridge additional connecting components such as the expansion joints that represent pounding elements aremodelled by linear spring elements, while the lead rubber bearings and restrainer cables are modelled by nonlinear springelements accounting the energy dissipation under strong motion. 


\subsubsection{Analytical modeling of restrainer cables elements}

Restrainer cable elements are devices which permitthe limitation of the deck longitudinal displacement and relative hinge openings in order to prevent unseating of bridge spans, or as fail-safe mechanisms to support bridge decks in case of unseating. They are often employed in bridges with insufficient seat widths and placed at the hinge locations at the deck abutment and deck-bent cap interfaces in the (MSSS) bridge considered herein. In general, the restrainer cables are employed in order to avoid unseating of the superstructure at the expansion joints.The restrainers alter the behavior of adjacent spans by transferring forces as the span opening exceeds the slack in the cable. Three types of restrainers are used in order to assess the seismic performanceofaMSSS bridge: the steel restrainer cables (SRC), the Shape Memory Alloy (SMA) bars in tension (SMA-T), and the SMA bars in bending (SMA-B) (Desroches and Delemont, 2002; Tazarv and Alam, 2018).

For the considered bridge, the SRC devicesconnecting the adjacent spans at the expansion jointsas shown in Fig. 1(b) are used herein in order to investigate the dynamicanalysis of a multi-span simply supported MSSS.

\subsubsection{Analytical modeling of pounding elements}

Two analytical methods are available for simulating the highly nonlinear behavior of pounding at the interfacesspan-abutment and span-span; the stereo mechanicalmethod and that of the contact element. The latter is activated when the collision occurs between decks/abutments and deck/deck of the bridge.The spring stiffness of pounding elementsis fixed proportionally to the axial stiffness of the neighboring structural segments, sometimes in combination with a damper (Kawashima and Shoji, 2000; Hong et al., 2019), the spring stiffness, $\mathrm{K}_{\text {gap }}$ is expressed as:

$K_{\text {gap }}=\gamma \frac{E A}{L}$

where $E A$ represents the axial stiffness of the cross-section of the superstructure, $\mathrm{L}$ is the length of the superstructure's element, and $\gamma$ is the ratio of impact spring stiffness to that of the superstructure.

The gap provided at the expansion joint is $11 \mathrm{cmand}$ adjacent spanscollision develop compressive forces when the relative displacement exhausts this gap width. It is modelled by the Kelvin model with stiffness $\mathrm{K}_{\text {Gap }}=45.87 \times 10^{6} \mathrm{KN} / \mathrm{m}$. The compressive forces $\left(f_{p}\right)$ for this model are expressed as follows (Desroche and Muthamar, 2004; Hong et al., 2019):

$$
\begin{gathered}
\text { If }(d-g a p)>0 f_{p}=K_{g} \times(d-g a p)+C \times(\dot{d}) \\
\text { Otherwise, } \quad f_{p}=0
\end{gathered}
$$

$d$ is given as.

$d=u_{i}-u_{j}$

$\dot{d}=\dot{u}_{i}-\dot{u}_{j}$

where $u_{i}$ and $u_{j}$ are the displacements of nodes $i$ and $j$ respectively, gap is separation between these nodes, $\dot{u}_{i}$ and $\dot{u}_{j}$ are the velocities of nodes $i$ and $j$ respectively.

The dashpot constant of the Kelvin model is calculated using these formulas

$$
C=2 \xi \times \sqrt{\left(K_{p} \frac{m_{1} m_{2}}{m_{1+} m_{2}}\right)}
$$


$\xi=-\frac{\ln (e)}{\sqrt{\left(\pi^{2}+\left(\ln (e)^{2}\right)\right)}}$

where $m_{1}$ and $m_{2}$ are the masses of the two impacting bodies, the constant (e) is the coefficient of restitution, for which the value is 1 for completely elastic impact and 0 for completely plastic impact (e.g. Anagnostopoulos and Spiliopoulos, 1992).

\subsubsection{Analytical modeling of LR Bearing devices}

Bridgesseismic isolation with Lead Rubber Bearings (LRBs) devices is an effective technique to passively reduce the seismic responses of the bridge. The LRB devices have a nonlinear behavior which may be idealized by a hysteretic bilinear model (see Figure 2).

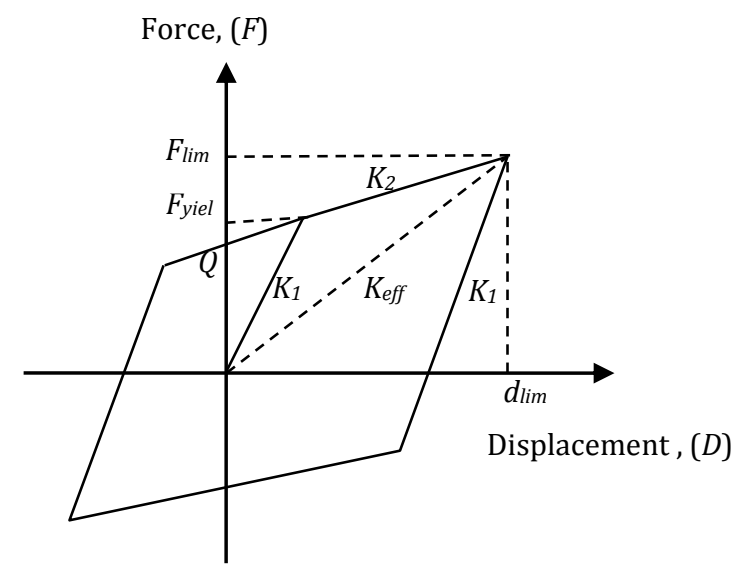

Fig 2. Characteristic curve of the LRB system: hystereticbilinear model.

The principal parameters that characterize the LRB analytical model are the elastic stiffness $\mathrm{K}_{1}$, corresponding to combined stiffness of the rubber bearing and the lead core, the stiffness of the rubber $\mathrm{K}_{2}$, and the yield force of the lead core $F_{\text {yield. }}$

The characteristic strength, $Q$ can be accurately estimated as being equal to the yield force of the lead core. $F_{l i m}$ and $d_{l i m}$ are respectively maximum force and maximum bearing displacement, $K_{\text {eff }}$ is effective stiffness of the LRB.

As a rule of thumb for lead-rubber isolators $K_{1}$ is taken as $10 K_{2}$, (FEMA, 2000; Xu Chena and Chunxiang, 2020).

The Table 1 reportes the parameter values adopted in this study of the LRB analytical modelin the longitudinal and lateral directions for a design displacement equal to $0.08 \mathrm{~m}$.

Table 1. Parameters of the bilinear model for LRB

\begin{tabular}{|c|c|c|c|c|c|c|}
\hline Direction & $\begin{array}{c}\mathrm{K}_{1} \\
(\mathrm{KN} / \mathrm{m})\end{array}$ & $\begin{array}{c}\mathrm{K}_{2} \\
(\mathrm{KN} / \mathrm{m})\end{array}$ & $\begin{array}{c}\mathrm{K}_{\text {eff }} \\
(\mathrm{KN} / \mathrm{m})\end{array}$ & $\begin{array}{c}\mathrm{Q} \\
(\mathrm{KN})\end{array}$ & $\begin{array}{c}\mathrm{F}_{\text {yield }} \\
(\mathrm{KN})\end{array}$ & $\mathrm{C}$ \\
\hline \hline Longitudinal and lateral & 1634 & 163.4 & 357.65 & 15.50 & & 85.33 \\
\hline
\end{tabular}

\subsubsection{Analytical modeling of dynamic soil structure interaction}

The complex dynamic impedance $\mathrm{Z}$ of the soil foundation is expressed as (e.g. Gazetas, 1991; Wolf, 1997):

$Z=K+i \omega C$ 
where $\mathrm{K}$ and $\omega C$ are real and imaginary parts of the dynamic impedance complex function, the damping coefficient $\mathrm{C}$ expresses the radiation that arise from waves emanating away from the foundation soil. Table 2 summarizes the relationships expressing the static stiffnesses of springs and damping coefficients corresponding to the six degrees of freedom at the base of the supports of bridge piers. (e.g. Ouanani and Tiliouine, 2015; Gazetas, 1991).

Table 2. Dynamic impedance complex function of foundation soil

\begin{tabular}{|l|c|c|}
\hline Degrees of freedom & Stiffness of foundation soil & Damping coefficient \\
\hline \hline Longitudinal direction & & \\
\hline \hline Lateral direction direction & $\mathrm{K}_{\mathrm{x}}=\frac{8 \mathrm{G}}{2-\mathrm{v}} \mathrm{R}_{\mathrm{x}}$ & $\mathrm{C}_{\mathrm{x}}=\frac{4.6 \mathrm{G}}{(2-v) V_{s}^{\prime}} R_{x}^{2}$ \\
\hline \hline Vertical direction & $\mathrm{K}_{\mathrm{y}}=\frac{8 \mathrm{G}}{2-\mathrm{v}} \mathrm{R}_{\mathrm{y}}$ & $\mathrm{C}_{\mathrm{y}}=\frac{4.6 \mathrm{G}}{(2-\mathrm{v}) \mathrm{V}_{\mathrm{s}}^{\prime}} \mathrm{R}_{\mathrm{y}}^{2}$ \\
\hline Rocking about the longutudinal, $\mathrm{X}$-axix & $\mathrm{K}_{\theta_{\mathrm{x}}}=\frac{4 \mathrm{G}}{1-\mathrm{v}} \mathrm{R}_{\mathrm{z}}$ & $C_{\mathrm{z}}=\frac{8 \mathrm{G}}{(1-v) \mathrm{V}_{s}^{\prime}} R_{\mathrm{z}}^{2}$ \\
\hline Rocking about the lateral, Y-axix & $\mathrm{K}_{\theta_{\mathrm{y}}}=\frac{8 \mathrm{G}}{3(1-\mathrm{v})} \mathrm{R}_{\theta_{\mathrm{y}}}^{3}$ & $C_{\theta_{x}}=\frac{0.4 G}{(1-v) V_{s}^{\prime}} R_{\theta_{\theta_{\mathrm{y}}}}^{4} \frac{0.4 \mathrm{G}}{(1-v) \mathrm{V}_{\mathrm{s}}^{\prime}} \mathrm{R}_{\theta_{\mathrm{y}}}^{4}$ \\
\hline Torque & $\mathrm{K}_{\theta_{\mathrm{z}}}=\frac{16 \mathrm{G}}{3} \mathrm{R}_{\theta_{\mathrm{z}}}^{3}$ & $C_{\theta_{\mathrm{z}}}=\frac{0.8 G}{V_{s}^{\prime}} R_{\theta_{\mathrm{z}}}^{4}$ \\
\hline
\end{tabular}

In Table $2, R_{x}, R_{\mathrm{y}}, R_{\mathrm{z}}, R_{\theta x}, R_{\theta \mathrm{y}}$ and $R_{\theta \mathrm{z}}$ are equivalent radii forarectangular foundation with dimensions L and B (L: long side dimension; B: short side dimension) (e.g. Fema 273, 1997; Gazetas, 1991; Wolf, 1997; Yohchia, 1997).

$v$ represents the Poisson's coefficient, whereas $G$ and $V_{s}^{\prime}$ designate the effective shear modulus and the effective shear wave velocity consistent with soil type and PGA design value.

The 2D-FEnonlinear analytical modelin the longitudinal direction of MSSS bridge modelled as lumped massas well as its connection components are detailed in Figure 3.

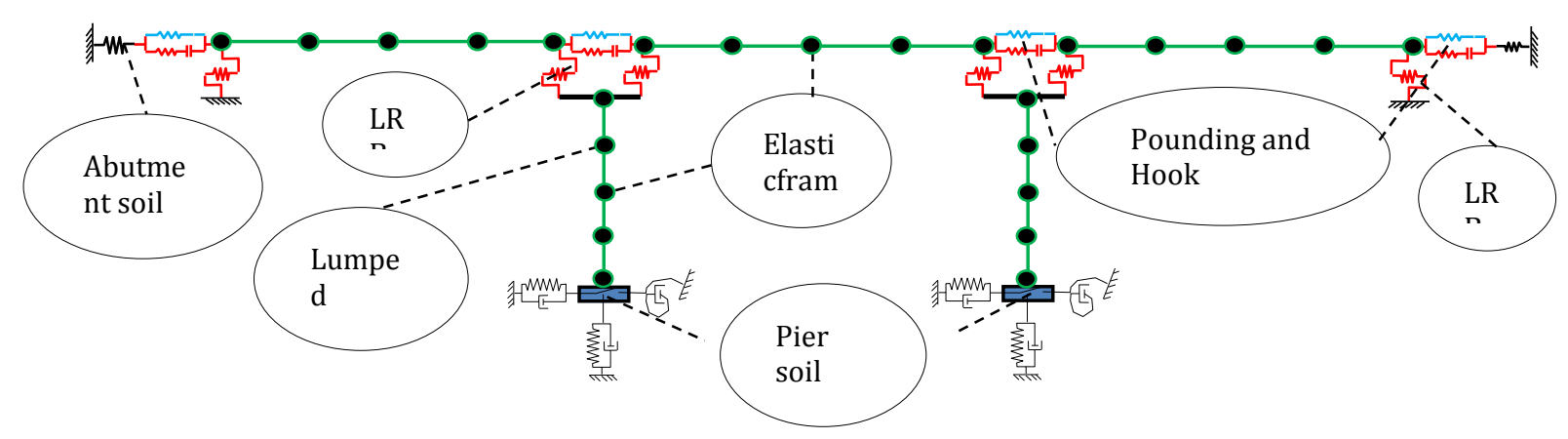

Fig 3. Detail's2D-FE non linear analytical model in the longitudinal direction of the MSS bridge and its Components

\section{Modal Analysis of aMSSS prestressed concrete bridge- foundation soil system}

For free vibration response analysis of a MSSS prestressed concrete bridge-foundation soil systems, the soil structure Interactionis essentially controlled by foundation soil flexibility which in turn is dependent onproperties of foundation soil.

In this study,the soil corresponding to the actual condition site construction for the considered bridge issoil type $S_{2}$ (firm site) in accordance with RPOA (2008); the weight density $\gamma=$ $21 \mathrm{KN} / \mathrm{m}^{3}$; Poisson's ratio $v=0.40$ and initial shear wave velocity $V_{s}=400 \mathrm{~m} / \mathrm{s}$. 
Moreover, the equivalent stiffness and damping coefficients of foundation soil are determined under a simulated accelerogram with PGA equal to $0.275 \mathrm{~g}$. The PGA consistent reduction factors for the effective shear modulus $G / G_{o}$ and the effective shear wave velocity $V_{s}^{\prime} / V_{S}$ are determined using a computer program (SHAKE) for earthquake response analysis of horizontally layered sites Schnabel et al. (1976).

The associated values of coefficients of stiffness and viscous damping foundation soil have been evaluated for soil type $S_{2}$ (firm site) with $G / G_{o}=0.55$ and $V_{s}^{\prime} / V_{S}=0.55$.

Table 3.Effective stiffness and effective damping constants of foundation soil.

\begin{tabular}{|c|c|c|c|c|c|c|c|c|}
\hline \multicolumn{3}{|c|}{$\begin{array}{l}\text { Rectangular spraed } \\
\text { footings }\end{array}$} & \multicolumn{3}{|c|}{ Translational stiffness $(\mathrm{KN} / \mathrm{m})$} & \multicolumn{3}{|c|}{ Rotational stiffness ( KN. m/rd) } \\
\hline $\mathrm{L}(\mathrm{m})$ & $\mathrm{B}(\mathrm{m})$ & e(m) & $\mathrm{K}_{\mathrm{x}} 3$ & $\mathrm{~K}_{\mathrm{y}} 2$ & $\overline{\mathrm{K}_{\mathrm{z}} 1}$ & $\mathrm{~K}_{\theta \mathrm{x}} 3$ & $\mathrm{~K}_{\theta \mathrm{y}} 2$ & 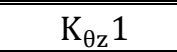 \\
\hline \multirow[t]{4}{*}{13.2} & 6.4 & 1.8 & 9277264 & 9055319 & 9717088 & 299229684 & 101021483 & 259074216 \\
\hline & & & \multicolumn{3}{|c|}{ Translational damping (KN.s/m) } & \multicolumn{3}{|c|}{ damping rotationnel (KN.m.s/rd) } \\
\hline & & & $\mathrm{C}_{\mathrm{x}}$ & $\mathrm{C}_{\mathrm{y}}$ & $\mathrm{C}_{\mathrm{z}}$ & $\mathrm{C}_{\theta \mathrm{x}}$ & $\mathrm{C}_{\theta \mathrm{y}}$ & $\mathrm{C}_{\theta \mathrm{z}}$ \\
\hline & & & 63027 & 63027 & 109612 & 848832 & 199542 & 629024 \\
\hline
\end{tabular}

In this study, numerical techniques (e.g. Wilson, 2002; Chopra, 2011) have been performed in order to identify the dynamic characteristics of the MSSS prestressed concrete bridge.

Table 4 lists the first eleven modal periods and the modal participation factors as well as the corresponding mode types denoted herein by $\mathrm{L}$ for lateral, Lg for longitudinal, $\mathrm{V}$ for vertical directions and $\mathrm{T}$ for torsional vibrations for the coupled bridge structure-foundation soil system.

In addition, the first 3-D modal characteristics of lateral, vertical, longitudinal and torsional vibrations of both symmetrical (S) and unsymmetrical (AS) higher modes of the bridge have been identified. A 3-D graphical representation of the corresponding mode shapes is presented in Figure 4.

Table 4. Modal periods and participation factors vibration modes

\begin{tabular}{|c|c|c|c|c|c|l|}
\hline $\begin{array}{c}\text { Modal } \\
\text { orders }\end{array}$ & $\begin{array}{c}\text { Period } \\
\text { (sec.) }\end{array}$ & \multicolumn{5}{|c|}{$\begin{array}{c}\text { Particiaption } \\
\text { factors(\%) }\end{array}$} \\
\hline \hline & & X-X & Y-Y & Z-Z & R-X & Mode types \\
\hline 1 & 3,445 & 64,8 & 0 & 0 & 0 & First-order Symmetric (S) Longitudinal vibration (Lg) \\
\hline 2 & 3,398 & 0 & 0 & 0 & 0 & First Anti symmetric (AS) Longitudinal vibration (Lg) \\
\hline 3 & 3,373 & 6,7 & 0 & 0 & 0 & Second-order Symmetric (S) Longitudinal vibration (Lg) \\
\hline 4 & 3,184 & 0 & 57,2 & 0 & 0,1 & First-order Symmetric (S) Lateral vibration (L) \\
\hline 5 & 2,518 & 0 & 0 & 0 & 0 & First-order Antisymmetric (AS) Lateral vibration (L) \\
\hline 6 & 0,504 & 0 & 0 & 56,4 & 0 & First-order Symmetric (S) Vertical vibration (V) \\
\hline 7 & 0,502 & 0 & 0 & 0 & 0 & First-order Antisymmetric (AS) Vertical vibration (V) \\
\hline 8 & 0,500 & 0 & 0 & 0,1 & 0 & Second-order Symmetric (S) Vertical vibration (V) \\
\hline 9 & 0,476 & 0 & 10,1 & 0 & 0,1 & Coupling modes of L and T vibrations \\
\hline 10 & 0,473 & 0 & 0 & 0 & 0 & First-order Antisymmetric (S) Torsional vibration (T) \\
\hline 11 & 0,468 & 0 & 0,8 & 0 & 3,2 & First-order Symmetric (AS) Torsional vibration (T) \\
\hline
\end{tabular}

From Table 4, it is clearly observed that the first three modes of vibration are longitudinal, which leads to a dynamic analysis in the longitudinal direction (i.e. in the most critical direction) of a multi-span simply supported MSSS prestressed concrete bridge equipped with restrainers and seismic isolation devices at expansion joints and abutments including Soil Structure Interaction (SSI) effects. 

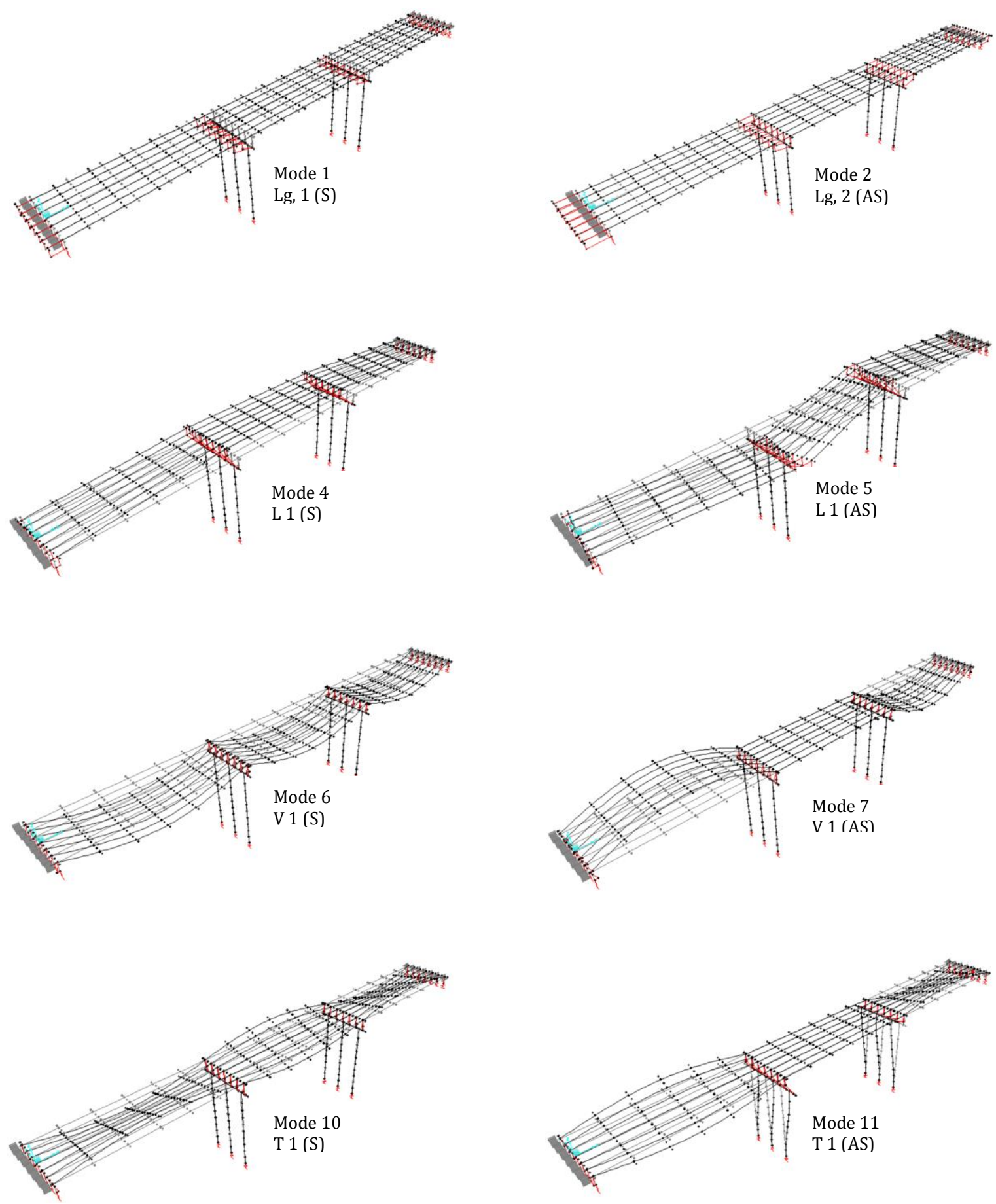

Fig 4. 3-D graphical representation of the mode shapes of both symmetrical (S) and unsymmetrical (AS) fundamental modes of vibration of the MSSS bridge 


\section{Dynamic analysis of a MSSS prestressed concrete bridge- foundation soil system}

In the second part of this study, the previous work is now extended to assesthe dynamic analysis of a MSSS prestressed concrete bridge with restrainers and seismic isolation devices including foundation soil flexibility subjected to a stochastically simulated earthquake based on the design spectrum for the soil type $S_{2}$ (firm site) in accordance with RPOA(2008).

Figure 5 show the simulated ground motion compatible with a design spectrum RPOA(2008) scaled by a factor of 2 (i.e. $\mathrm{PGA}=0.55 \mathrm{~g}$ ).

Time (sec.)

Fig 5. (a) Simulated ground motion, (b) Response spectra and design spectrum RPOA(2008) of the simulated ground motion

For time history analysis of the study bridge response, the mass and stiffness proportional Rayleigh damping coefficients were determined considering the first two modal periods assuming a $5 \%$ viscous damping ratio.

The dynamic equations of motion are solved numerically using Newmark'snumerical method (Zienkiewicz and Taylor, 2005; Newmark, 1962).

\subsection{Effect of pounding on the gap relativedisplacement}

The absolute maximum gap relative displacements of expansion joints at abutments and at intermediate bentsof the MSSS bridge with and without completely elastic pounding are determined in the longitudinal direction (i.e. in the most critical direction). The results obtained are reported in Table 5.

Table 5. Effect of pounding on the absolute maximum gap relative displacements $(\mathrm{m})$ of the girders.

\begin{tabular}{|c|c|c|c|c|c|c|}
\hline Locations & \multicolumn{2}{|c|}{ Abutment expansion joints } & \multicolumn{3}{c|}{ Multi-column bents } \\
\hline \hline Girders locations & Corner & Intermediary & Central & Corner & Intermediary & Central \\
\hline Without pounding & $\mathbf{0 . 2 0 5 4}$ & 0.2036 & 0.2000 & $\mathbf{0 , 0 3 0 1}$ & 0,0252 & 0,0175 \\
\hline With pounding & $\mathbf{0 , 1 1 0 8}$ & 0,1029 & 0,1015 & $\mathbf{0 , 0 3 8 9}$ & 0,0347 & 0,02553 \\
\hline
\end{tabular}

From Table 5 it is clear that the absolute maximum gap relative displacement is larger at abutment expansion joints, especially in the corner girder. By comparing the pounding effects, we can also see that the absolute maximum gap relative displacements are reduced at abutments and amplified at bents when the pounding effects are considered.

For illustration purposes, the time history responses of bridge in term of relative displacements without and with pounding are depicted in Figures 6(a) for expansion joints of abutments and in 6(b) for expansion joints of intermediary multi-column bents of the study bridge. 
It observed that the pounding effects generally lead to a decrease in gap relative displacements at the joint expansions of abutments (see Figure 6(a)) and an increase at the expansion joints of bents (see Figure 6(b)).

Time (sec.)

Fig 6. Time history response of absolute maximum relative displacement; (a) Expansion joints of abutments, (b) Expansion joints of intermediate multi-column bents

\subsection{Effect of pounding on the peak LRB shear strain}

The maximum shear strains in the longitudinal direction of lead rubber bearings LRB located at abutments and multi-column bents of the MSSS bridge with and without pounding are given in Table 6 below.

Table 6. Effect of pounding on the maximum shear strain of lead rubber bearings (in \%)

\begin{tabular}{|c|c|c|c|c|c|c|}
\hline Locations & \multicolumn{3}{|c|}{ Abutment expansion joints } & \multicolumn{3}{c|}{ Multi-column bents } \\
\hline \hline Girder locations & Corner & Intermediary & Central & Corner & Intermediary & Central \\
\hline Without pounding & 413 & 409 & 377 & 442 & 440 & 435 \\
\hline With pounding & 244 & 241 & 303 & 245 & 248 & 252 \\
\hline
\end{tabular}

It is seen that the maximum values of bearings shear strain located on abutments and multicolumns bent are more prounced when the pounding effects are negleted.

Moreover and for the purpose of illustration, Figures 7(a) and 7(b) below show the time-history response in the longitudinal direction of LRB seismic isolation devices at abutment back wall and multi-column bents.

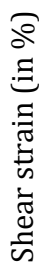

Time (sec.)

Fig. 7. Time history response of shear strain response of LRB seismic isolation device at abutments (a) multicolumns bent (b) of bridge model.

\subsection{Effect of restrainer on the relative displacement of expansion joints}

The restrainers used in seisimic design of the study bridge are steel cables. The latters are modelled as a multi-linear model with strain hardening andthe axial forces are generated when restrainers get engaged by loosing the initial slack of $15 \mathrm{~mm}$. The yield force of restrainers is 
$2640 \mathrm{KN} / \mathrm{m}$ and initial modulus of elasticity is equal to $69000 \mathrm{MPa}$. The initial stiffness of the restrainers of $30 \mathrm{kN} / \mathrm{mm}$ and a strain hardening of $5 \%$ is assumed.

Figure 8 below, depict the temporal variations of relative displacements of expansion joints at abutments and intermediate multi-column bents of the MSSS bridge with and without restrainers.

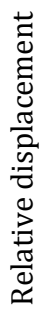

Fig 8. Time history response of absolute maximum relative displacement; (a) Expansion joints of abutments, (b) Expansion joints of intermediary multi-column bents

From Figure8(a) it is seen that the values of relative displacements of expansion joints of abutments are reduced (indicated by the dash-dotted line) when using the restrainers combined with pounding elements and seismic isolation bearings.Similar trends are observed in the expansion joints of intermediary multi-column bents (see Figure 8(b)).

We can summarize that the restrainers could control the expansion joint opening deformation and secure the unseating of the bridge deck on the expense of the increase of shear and moment seismic demand of the supporting pier at the expansion joint.

\subsection{Effect of restrainer on the shear strain response of LRB seismic isolation device}

In order to understand the influence of restrainer cables on the LRB seismic isolation device response in the longitudinal direction for study bridge under simulated earthquake, shear strains time variations for these isolators at abutments and bents are plotted in Figure 9.

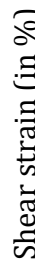

Fig 9. Time history response of shear strain response of LRB seismicisolation device of bridge model (a) at abutments (b) at multi-columns bent.

From Figure 9(a) it is observed that, there is a significant reduction of LRB isolators shear strains at abutments due to the application of restrainer cable system. The bearing peak shear strain at abutment locations is found to be $240 \%$ for bridge without the restrainer cables, while it is equal to $132 \%$ for bridge with restrainer cables which corresponds to significant decreases of $45 \%$ when the restrainer cables system is considered. Similar conclusions can be drawn for LRB isolators shear strainsat multi-columns bents Figure 9(b).

Therefore, the restrainer cables tend to reduce the earthquake forces induced in the seismicisolation system of a multi-span simply supported bridge. Under extreme seismic 
excitations, the maximum bearing shear strain is a quantity of prime interest in the seismic design of bridge structures because if it exceeds certain limits, the bearings may fail resulting into the bridge collapse.

\subsection{Effect of restrainers on pounding forces}

The gap element is provided to take care of pounding effects between the abutment-deck and deck-deck. The initial gap provided in the gap element is $0.10 \mathrm{~m}$ and pounding develops the compressive forces at the interfaces when the relative displacement exhaust this initial gap width. It is modeled by introducing a linear spring with stiffness $K_{\text {Gap }}=3790622 \mathrm{KN} / \mathrm{m}$ at abutments and equal to $1895511 \mathrm{KN} / \mathrm{m}$ at bents.

To investigate the effect of restrainer cables on the pounding response at deck-abutment and deck-deck interfaces of MSSS bridge, the temporal variations of the pounding forces without and with restrainers are presented in Figure 10.

Pounding

$18646 \mathrm{kN} \bigcirc$

$41064 \mathrm{kN} \bigcirc$
Time (sec.)

$\times 10^{-3}$

Fig 10. Time history response of pounding forces of bridge model(a) at abutments (b) at multi-columns bents.

From Figure 10 (a), it can be noticed that the restrainer cables reduce significantly the values of pounding forces at the interface of abutment-deck of study MSSS bridge. The maximum pounding force is found to be $41064 \mathrm{kN}$ for bridge without restrainers, while it is equal $18646 \mathrm{kN}$ when the bridge spans are connected with restrainer cables system. Similar conclusions can be drawn for pounding forces at multi-columns bents (see Figure 10(b)). From the same Figure, it is seen that, there is a substantial $23 \%$ reduction in the peak pounding forces at multi-columns bents due to restrainer cables effects.

It can be concluded that the maximum pounding force at expansion joints of a multi-span simply supported MSSS concrete bridge is obviously reduced using restrainer cables system.

\section{Summary and Conclusions}

In this paper, an extensive numerical investigation on the dynamic analysis of a multi-span simply supported MSSS prestressed concrete bridge with expansion joints and lead rubber bearing devices including foundation soil flexibility effects are presented. In this context, the 3D Finite Element Model FEM of a MSSS bridge subjected to a 3D components of severe seismic excitation is performed in order to assess the performance of steel restrainer cables and Lead Rubber Bearing devices LRB. The Nonlinear hysteretic models characterizing the seismic behavior of various bridge components (including expansion joints and bearing devices) are considered.

The effects of restrainer cables and pounding forces on the MSSS bridge behavior are discussed, and the following conclusions are drawn:

1. The first three dominant modes of the bridge are in the longitudinal directions which to assess a dynamic analysis in this direction (i.e. in the most critical direction). 
2. Pounding effects generally lead to a decrease in gap relative displacements at abutment joint expansions and increase at bent expansion joints.

3. The computed maximal shear strainsof LRB in the longitudinal direction are more prounced when the pounding effects are negleted.

A comparative assessment of behaviour of expansion joints, lead rubber bearing devices and steel restrainers components showsthat under this study:

i. The restrainers could control the expansion joint opening deformation and secure the unseating of the bridge.

ii. The steel restrainer cables tend to reduce the earthquake forces induced in the seismic isolation devices LRB of a multi-span simply supported bridge.

iii. Under extreme seismic excitations, the peak shear strain at bearing devices is a quantity of prime interest in the design of bridge structures because if it exceeds certain limits, the bearings may fail resulting into the bridge collapse.

iv. The maximum pounding forces at expansion joints of a multi-span simply supported MSSS concrete bridge are obviously reduced using restrainer cables system.

It follows that in order to ensure an acceptably safe structural performance of aMSSSprestressed concrete bridge with expansion joints and seismic isolationsystem LRB at abutments, due consideration should be given at design stage to:

- Sound evaluation of distortion limits of seismic isolation bearings LRB at expansion joints and the restrainers components capacities at expansion joints.

- Using restrainers combined with the seismic isolation systems at bridge expansion joints could be an effective method of reducing the large pounding forces and preventing unseating damage.

\section{References}

Anagnostopoulos, SA. \& Spiliopoulos, KV. (1992) An investigation of earthquake induced pounding between adjacent buildings. Earthquake eng. struct dyn., 21, 289-302.

Association Francaise de Génie Prasismique AFPS (2003). Séisme de Boumerdes du 21 Mai 2003: Rapport préliminaire de la mission AFPS Organisée avec le concours du Ministère de l'Habitat.

Bi, K.M., Hao, H. \&Chouw, N. (2013). 3D FEM analysis of pounding response of bridge structures at a canyon site to spatially varying ground motions. Advances in Structural Engineering, 16 (4), 619640.

Chopra, A. K. (2011). Dynamics of structures: Theory and applications to earthquake engineering. Prentice-Hall, New Jersey, USA.

Chouw, N. (1995). Effect of the earthquake on 17th of January 1995 on Kobe. In Proceedings of the D-A-CH Meeting of the German, Austrian and Swiss Society for Earthquake Engineering and Structural Dynamics, University of Graz, Austria, pp. 135- 169.

CSI Bridge 2015 V 17.2.0 . Computer and Structures Inc. SAP2000 (Nonlinear Version 15), Nonlinear user's Manual Reference. USA.

Desroches, R. \& Delemont, R. (2002). Seismic retrofit of simply supported bridges using shape memory alloys. Engineering structures, 24, 325-332.

Desroches, R. \& Muthukumar, S. (2004) Implications of seismic pounding on the longitudinal response of multi-span bridges-an analytical perspective. Earthquake engineering and engineering vibration, 3, 57-65.

FEMA 273 NEHRP (1997).Guidelines for the Seismic Rehabilitation of Buildings, Federal Emergency Management Agency.Washington D.C, USA. 
FEMA-356 (2000). Prestandard and commentary for seismic rehabilitation of buildings, Federal Emergency Management agency, Washington, DC, USA.

Gazetas, G. (1991). Foundation Vibrations: chapter 15, In Foundation Engineering Handbook, H-Y Fang HY, Van Nostrand Reinhold, New York.

Hong, Y.J., Xian, L.L., Nan L., Jian, Y., Shi-Xiong, Z. \& Chao, Z. (2019). Nonlinear pounding analysis of multispan and simply supported beam bridges subjected to strong ground motion. Shock and vibration, $1-11$.

Hung, C. J. Lin, H., Liu, Y. \& Chai, J. (2008, October). Reconnaissance report of 0512 China Wenchuan earthquake on bridges. In Proceedings of the 14th World Conference on Earthquake Engineering, Beijing, China.

Kawashima, K. \& Shoji, G. (2000, February). Effect of restrainers to mitigate pounding between adjacent decks subjected to a strong ground motion. Proceedings of 12th world conference on earthquake engineering, Auckland, New Zealand.

Newmark, N. M. (1962). A Method of computation for structural dynamics," Trans. ASCE, 127.

Ouanani, M. \& Tiliouine, B. (2015). Effects of foundation soil stiffness on the 3-D modal characteristics and seismic response of a highway bridge. Journal of Civil Engineering KSCE, 19(4), 1009-1023.

Ouanani, M. \& Tiliouine, B. (2017). Progressive seismic failure of a highway bridge, including abutmentbackfill interaction. Current science, 112(2), 355-363.

RPOA (2008). Règles Parasismiques Applicables au Domaine des Ouvrages d'Art. Document Technique Règlementaire, Ministère des Travaux Publics, Alger, Algeria.

Schnabel, P. B., Lysmer, J. \& Seed, H.B. (1976). A Computer Program for Earthquake Response Analysis of Horizontally Layered Sites (SHAKE), Report (EERC 72 12), Earthquake engineering research center, University of California, Berk'eley.

Shinozuka, M., Murachi, Y., Dong, X., Zhou, Y. \&Orlikowski, M. (2003) Effect of seismic retrofit of bridges on transportation networks. Earthquake engineering and engineering vibration , 2, 69-179.

Tazarv, M. \& Alam, S. (2018, June). Shape memory alloy for bridge columns. Proceedings of the eleventh U.S. National conference on earthquake engineering, CA, USA.

Tiliouine, B.\&Ouanani, M. (2012, September). 3-D nonlinear earthquake response of R.C. box girder bridges with expansion joints and bearing devices. 15th world conference on earthquake engineering, Lisbon, Portugal.

Todd, D., Carino, N., Riley, M., Chung, H. S., Andrew, W., William, D., James, D., and Roland, N. (1994). The Northridge, California, Earthquake of January 1994: Performance of Structures, Lifelines, and Fire Protection Systems. National Institute of Standards and Technology (NIST), USA.

Uzarski, j. \& Arnold, C. (2001). Chi-chi, Taiwan, earthquake of September 21, 1999: reconnaissance report. Earthquake spectra, supplement, Taiwan.

Wilson, E. L. (2002). Three-dimensional static and dynamic analysis of structures: a physical approach with emphasis on earthquake engineering. Computer and Structure, Inc. Berkeley, California, USA.

Wolf, JP. (1997). Springs-Dashpots-Mass models for foundation vibration. Earthquake engineering and structural dynamics, 26, 931-949.

Xu Chena, B. \& Chunxiang, Lib. (2020) Seismic performance of tall pier bridges retrofitted with lead rubber bearings and rocking foundation. Engineering structures, 212, 1-15.

Yang, Z., Kun, C \& Chouw, N. (2018, December).Impact of spatial variation of ground motions on the seismic performance of a bridge structure. 25th Australasian Conference on Mechanics of Structures and Materials (ACMSM25), Australia.

Yohchia, C. (1996). Modeling and analysis methods of bridges and their effects on seismic responses: I Theory. Computers and structures, 59(1), 81-89. 
Zienkiewicz, O.C. \& Taylor, R.L. (2005). The Finite element method, solid mechanics. Upper Saddle River, New Jersey, USA. 